\title{
The Lebanese nautical cartographic plan development
}

\author{
Marta Pratellesi $^{\mathrm{a} * *}$, Manuela Milli ${ }^{\mathrm{a}}$, Afif Ghaith ${ }^{\mathrm{b}}$, Christian Fahed $^{\mathrm{b}}$ \\ ${ }^{a}$ Italian Hydrographic Institute, Passo all'Osservatorio 4, 16136 Genova, Italy. \\ e-mail:*marta.pratellesi@marina.difesa.it,manuela_milli@marina.difesa.it \\ ${ }^{b}$ Lebanese Navy Hydrographic Service, Beirut Naval Base Chafic al Wazzan Street, Beirut, Lebanon. \\ e-mail:afifg@hotmail.com,christian_fahed@hotmail.com \\ * Corresponding author
}

Keywords: cartographic plan, capacity building, hydrography, IHO standard.

\begin{abstract}
:
The Italian-led capacity building project aimed at creating the Lebanese hydrographic service, has resulted in significant outcomes in terms of Lebanese technical capabilities development and consolidation of the effectiveness of the maritime capacity building model implemented by the Italian Hydrographic Institute. These results emerged with extraordinary force in the moment of the emergency caused by the explosions in the port of Beirut on the $4^{\text {th }}$ of August 2020 which created significant damage to the port and the city. The Lebanese Navy Hydrographic Service (LNHS) has shown that it has the ability to independently carry out hydrographic surveys as well as the ability to give them the appropriate cartographic restitution, capabilities that have allowed Lebanon to become, in December 2020, the $94^{\text {th }}$ member country of the International Hydrographic Organization (IHO).
\end{abstract}

Over the last 6 years (2014-2020), the commitment made by the Italian Navy, through the Italian Hydrographic Institute (IIM), National Cartographic body for the maritime domain, has led Lebanon to acquire autonomous capabilities in the conduct of hydrographic surveys and in the enhancement of the relative data, starting also the necessary creation of the geographical references to which to relate the measurements for the subsequent production of nautical, digital and traditional cartography. The Italian-Lebanese cooperation in the cartographic field began in 2014, foundation year of the LNHS, and is configured in a more ambitious and complex framework of activities in support of Lebanon through the enhancement and development of autonomous capacities. The Italian Hydrographic Institute proposed a Capacity Building project based on three pillars: training, acquisition of hydrographic capacity, creation of an autonomous hydrographic service and implementation of a geographic data infrastructure that allows Lebanon to guarantee the safety of navigation in waters of national jurisdiction in accordance with SOLAS 74/78.

Italy, as a member of the IHO, through the IIM, approached this cooperation project, first of all laying the foundations for a partnership that was strengthened with the signing, in July 2020, of a Technical Agreement (TA) between the Italian and Lebanese Ministries of Defense in the fields of Hydrography, Oceanography and Nautical Cartography.

Cooperation is still ongoing and focuses on the improvement of a Lebanese nautical cartography plan.

In full respect of the role of the nation, the IIM has made itself fully available to assist the LNHS in defining the nautical cartography plan and in its implementation.

The LNHS area of competence amounts to $22.700 \mathrm{~km}^{2}$ stretched along $230 \mathrm{~km}$ of coast and the charts portfolio will be developed starting with the production of the Electronic Nautical Charts (ENCs) from which traditional Paper Charts (PCs) will be derived.

The Lebanese Nautical Charting Plan is composed of 3 series of ENCs and Paper Charts (Table 1) in accordance with the navigational requirements of shipping. During the definition of the charting plan, a set of medium and large-scale charts was specifically designed for port entry, approaches to ports and major shipping areas, and coastal shipping routes.

\begin{tabular}{|l|l|l|}
\hline Series & Puropose & Scale \\
\hline LB 300 & Coastal & $1: 100.0001: 250.000$ \\
\hline LB 400 & Approach & $1: 25.0001: 50.000$ \\
\hline LB 500 & Harbour & $1: 5.000-1: 10.000$ \\
\hline
\end{tabular}

Table 1. Charts and ENCs series

The Lebanese PCs and ENCs scheme, compliant with the IHO's standard, is summarized in the Tab.2 and shown in Fig.1. 
It describes a strategy to create a comprehensive "Nautical Charting Plan” to be developped in the next decade (20212031) together with a suite of nautical publications.

In early May the production of the ENC of the port of Beirut has started with a collaboration of professional staff from IIM and LNHS.

\begin{tabular}{|c|c|c|c|c|}
\hline ENC & PC & Title & Scale ENC & Scale PC \\
\hline LB300301 & LB 301 & Tripoli to Ras es Saadiyat & $1: 90.000$ & $1: 100.000$ \\
\hline LB300302 & LB 302 & Ras El Maameltein to Ras Al Naqourah & $1: 90.000$ & $1: 100.000$ \\
\hline LB300303 & LB 303 & Baniyas to Akko & $1: 180.000$ & $1: 250.000$ \\
\hline & \multirow{3}{*}{ LB 401} & Approach to Tripoli and Selaata & & \\
\hline LB40401A & & Approach to Tripoli (A) & $1: 45.000$ & $1: 40.000$ \\
\hline LB40401B & & Approach to Selaata (B) & $1: 22.000$ & $1: 20.000$ \\
\hline LB400402 & \multirow{2}{*}{ LB 402} & Approach to Beirut and Port of Jounieh & $1: 45.000$ & $1: 40.000$ \\
\hline LB50402A & & Port of Jounieh (A) & $1: 12.000$ & $1: 12.000$ \\
\hline LB400403 & LB 403 & Approach to Sidon & $1: 22.000$ & $1: 25.000$ \\
\hline LB400404 & LB 404 & Approach to Tyre & $1: 22.000$ & $1: 25.000$ \\
\hline LB500501 & LB 501 & Port of Tripoli & $1: 6.000$ & $1: 8.000$ \\
\hline LB500502 & LB 502 & Port of Beirut & $1: 6.000$ & $1: 8.000$ \\
\hline LB500503 & LB 503 & Port of Sidon & $1: 4.000$ & $1: 6.000$ \\
\hline
\end{tabular}

Table 2. List of Lebanese paper charts and ENCs.

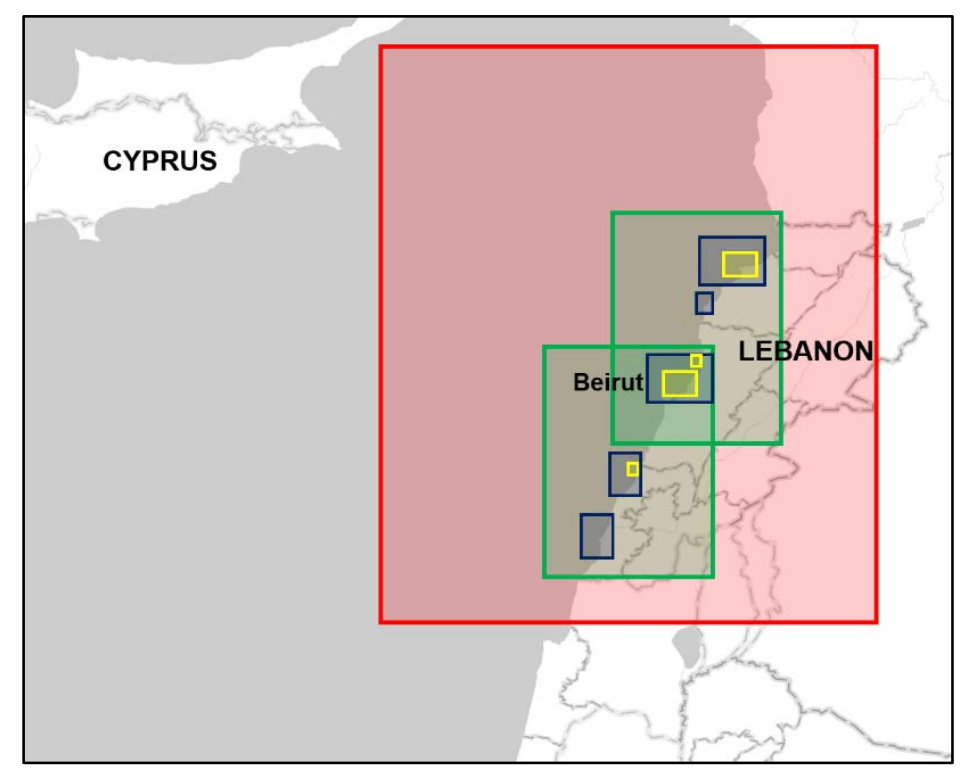

Fig.1 Paper charts and ENCs schemed

\section{References:}

- Technical Arrangement between the Ministry of National Defence of the Lebanese Republic and the Ministry of the Defense of the Italian Republic in the field of Hydrogrpahy, Oceanography and Nautical Cartography (July 2020).

- IHO (2018). Regulations of the IHO for International (INT) charts and chart specifications of the IHO. Publication S-4. Ed. 4.8.0.

- IHO (2018). Guidance for the preparation and maintenance of international (INT) chart and ENC schemes and catalogue of international charts. Publication S-11-Part A. Ed. 3.1.0.

- IHO (2017). ENCs: Production, maintenance and distribution guidance. Publication S-65 Edition 2.1.0.

- IHO (2000). IHO Transfer standard for digital hydrographic data. Publication S-57 Ed.3.1. 